New Drug Update

\title{
An analgesic to bridge the gap between Narcotics and NSAIDs: opiorphin
}

\author{
Sujatha S. ${ }^{1 *}$, Priyadharshini R. ${ }^{1}$, Niloofar Khansari Nejad ${ }^{2}$, Yashoda Devi B. K. ${ }^{1}$, Shwetha V. ${ }^{1}$, \\ Pavan Kumar T. ${ }^{1}$, Rizwana Azmi ${ }^{1}$
}

${ }^{1}$ Department of Oral Medicine and Radiology, ${ }^{2}$ Department of Dental Sciences, Ramaiah University of Applied Sciences, Bangalore, Karnataka, India

Received: 25 April 2018

Revised: 03 May 2018

Accepted: 23 May 2018

*Correspondence to:

Dr. Sujatha S.,

Email: s_sujathajanardhan@ yahoo.com

Copyright: (C) the author(s), publisher and licensee Medip Academy. This is an openaccess article distributed under the terms of the Creative Commons Attribution NonCommercial License, which permits unrestricted noncommercial use, distribution, and reproduction in any medium, provided the original work is properly cited.

\begin{abstract}
Pain management is an all-time challenge in dentistry. Discontent to pain management is a concern among patients and professionals. Unrelieved pain affects physical and mental well-being contributing to delayed recovery, psychological distress and anxiety. Studies have revealed that chronic pain interferes with normal daily chores of the individual like exercise, sleep, social life and lifestyle. At one end of pain management spectrum are Non-steroidal anti-inflammatory drugs (NSAIDs) while at the other end are the opioids. These drugs are not without constituent side effects. The quest is for new analgesics with potent and long term analgesia with minimal or no side effects. An analgesic that is intermediate in this spectrum is the need of the hour. Opiorphin is an endogenous peptide isolated from human saliva. Opiorphin produces analgesia, by inhibiting enkephalin (ENK) metabolizing enzymes, thus increasing the halflife of circulating ENKs. Apart from being a potent analgesic it can also be a potential biomarker for various systemic and psychosocial disorders. This review focuses on the pharmacological effects of opiorphin and its potential role as a biomarker in various disease conditions.
\end{abstract}

Keywords: Analgesics, Enkephalinase inhibitors, Endogenous opioids, Enkephalins, Opiorphin

\section{INTRODUCTION}

Pain is a distressing experience associated with actual or potential tissue damage with sensory, emotional, cognitive and social components. ${ }^{1}$ While acute pain is self-limiting, concordant with the degree of on-going tissue damage, remitting with resolution of the injury, chronic pain is not self-limiting and, if inadequately treated, leads to peripheral and/or central nociceptive sensitization. The treatment of acute and chronic pain, especially in terminally ill patients, is still inadequate, despite the great and extensive efforts made in this regard at both scientific and economic levels. The search for newer and more effective treatments against pain is of fundamental importance not only from an ethical point of view, but also for economic reasons. The International Association for the Study of Pain (IASP) survey revealed that lack of education, inadequate government policies, fear of opioid addiction, high cost of analgesics, and poor patient compliance are major barriers for optimal pain management in developing countries. ${ }^{2}$

Pain is modulated by two primary types of drugs that work on the brain: analgesics and anesthetics. The term 
analgesic refers to a drug that relieves pain without loss of consciousness. Opioid receptor agonists, such as morphine or its alternates are being considered as the most competent drugs to relieve pain. However, their clinical usefulness is limited by the development of tolerance, dependence, hyperalgesia, constipation and respiratory depression. ${ }^{3}$ In spite of this, morphine and its surrogates remain the most sort after drugs for pain management. Any drug able to generate fewer side effects than morphine, at equal analgesic doses, would therefore enhance the quality of life of these patients.

\section{OPIORPHIN: THE PROMISING ALTERNATIVE}

Opiorphin is an endogenous peptide isolated from human saliva in 2006. It dually inhibits ENK-inactivating human neutral endopeptidase (NEP) and aminopeptidase-N (APN). It is a QRFSR pentapeptide. Human opiorphin is described as "a natural antinociceptive modulator of opioid-dependent pathways". Opiorphin is a peptide of five amino acids present under 2 forms of amino acid sequence Gln-Arg-Phe-Ser-Arg and pGlu-Arg-Phe-SerArg. It was first extracted, purified and characterized by a functional biochemical approach from human saliva. ${ }^{4-7}$ The precursor of opiorphin peptide is PROL1 gene which is expressed by lacrimal glands and salivary glands. The opiorphin modulates chemical-and mechanical-evoked pain by activating endogenous opioid-dependent pathways. It's analgesic effects are specifically mediated via endogenous ENK-dependent activation of $\mu$-opioid receptor and $\delta$ opioid receptor pathway. Opiorphin-derived peptide inhibits nociception induced by acute and longacting chemical stimuli. ${ }^{5-7}$

Morphine and its surrogates exert their action through opioid receptors identified as: $\mu$-mu, $\delta$-delta and $\kappa$-kappa which are widely distributed in the brain. Subcortical regions of the brain (thalamus, periaqueductal gray, rostral ventromedial medulla, and locus ceruleus) and dorsal horn region of the spinal cord (laminae I and II) constitute the primary area of concentration of opioid receptor. These receptors are localized on presynaptic afferent fibers, interneurons, and postsynaptic projection neurons. ${ }^{3,8}$

In the Central Nervous System (CNS) endogenous opioid peptides have been recognized that interact with the above opiate receptors. They include: $\beta$-endorphins, ENKs and the dynorphins. Morphine acts by directly stimulating $\mu$ opiod receptor which are also activated physiologically by ENKs (Met and Leu-ENKs). These opioid peptides, expressed as preproenkephalin, are processed within specific neurons and released through a $\mathrm{Ca}^{2+}$ dependent mechanism, to interact with two $G$ protein-coupled receptors, the $\mu$ and $\delta$-opioid receptors and act as physiological regulators of pain. The most important endogenous opioid peptides, the ENKs, play a major role in the dynamic control of pain perception. ENKs interact with high affinity, both $\mu$ and $\delta$ opioid receptors, present on synaptic membranes of opioid and target neurons. The affinity of ENKs for $\mu$ receptors is similar to that of morphine and is 10 -fold higher for $\delta$ receptors. The high intrinsic efficacy of ENKs as compared to morphine necessitates that ENKs need to occupy a smaller proportion of opioid receptors than morphine to elicit the same antinociceptive responses. ${ }^{8,9}$

It has been observed that intracerebroventricular administration of ENKs in animal models of acute pain induced antinociceptive responses similar to morphine. However, this effect was transient due to the rapid enzymatic degradation of ENKs. In vivo, ENKs are inactivated by two membrane-bound Znmetallopeptidases, neprilysin (NEP, EC 3.4.24.11), which cleaves the Gly3-Phe4 bond, and aminopeptidase N (APN, EC 3.4.11.2). ${ }^{9}$

Accordingly, selective and potent inhibition of both ENK metabolizing peptidases largely increases extracellular concentrations and half-life of ENKs released in response to a noxious stimulus. Increasing the lifetime of circulating ENKs, released in response to nociceptive stimuli, by inhibiting their degradation is, therefore, an effective method to increase their bioavailability and thus to enhance their physiological actions and particularly their analgesic potency. The discovery of such novel endogenous upstream regulators in human, is of crucial interest from physiological and therapeutic point of view.

This is achieved by inhibition of their enzymatic degradation by two membrane-bound Znmetallopeptidases, neprilysin (NEP, EC 3.4.24.11) and aminopeptidase $\mathrm{N}$ (APN, EC 3.4.11.2). Opiorphin analgesic effect is caused by protection of the endogenous ENKs released after pain stimuli and potentiation of ENKdependent antinociception. Opiorphin activates opioid receptor-dependent pathways indirectly by increasing the longer term action of endogenous ENKs released in response to painful stimuli.

\section{PHARMACOLOGICAL PROPERTIES OF OPIORPHIN: KINETICS, DYNAMICS AND THERAPEUTICS}

Table 1: Opiorphin levels in various human biological fluids.

\begin{tabular}{|ll|}
\hline Biological medium & Opiorphin level $(\mathrm{ng} / \mathrm{ml})$ \\
\hline Saliva & $2.8-25.9$ \\
\hline Blood & $0.3-1.1$ \\
\hline Milk & $3-23$ \\
\hline Semen & $3-8.5$ \\
\hline Lacrimal fluid & $2-183$ \\
\hline Urine & $8.3 \pm 1.5$ \\
\hline
\end{tabular}

The pain alleviating potency of $1 \mathrm{mg} / \mathrm{kg}$ of opiorphin is equivalent to $6 \mathrm{mg} / \mathrm{kg}$ of morphine. The antihyperalgesic potency induced by opiorphin remains stable for at least 4 days. In contrast to morphine, opiorphin lacks the development of tolerance. The absence of adverse effects, 
such as respiratory depression, and of major hemodynamic disturbances after continuous systemic treatment with opiorphin may be due to the limited and targeted stimulation of ENK-dependent opioid receptors. ${ }^{5}$

The anti-depressant like action of opiorphin has also been demonstrated in rats by forced swim test. The antidepressant-like effect was elicited with $1-2 \mathrm{mg} / \mathrm{kg}$ human opiorphin i.v. doses in habituated rats and was completely reversed by the selective delta-opioid receptor antagonist, naltrindole (10mg/kg i.p.). The antidepressant like effect of opiorphin through central administration is contributed by activation of both $\mu$ and $\delta$ opioid receptor while the same effect through peripheral administration is by activation of $\delta$ opioid receptor only. The antidepressant like effects of opiorphin is attributed to the activation of endogenous $\delta$ - opioidergic pathways. ${ }^{10,11}$ A severe side effect limiting the activation of $\delta$ opioid receptor for treating depression is convulsion. This effect was notably absent while using RB101, which is a synthethically prepared dual inhibitor of APN and NEP. ${ }^{8,11}$

Studies on plantar incision-induced pain rat model showed that opiorphin do not cause respiratory depression, maintains stable post-operative haemodynamic status and also lacked anti peristaltic effect. ${ }^{4}$

Opiorphin effectively crosses the Blood-Brain-Barrier (BBB) where in N-terminal glutamine form of opiorphin is converted into the pyroglutamate form. STR-324 is the cyclized form of the N-terminal glutamine 1-opiorphin, resulting in the pyroglutamate 1 peptide. Intravenous infusion of tritiated STR-324 in monkeys, a selective sequestration of the radioactive peptide was observed in the spinal and cerebral tissues indicating its ability to cross BBB. ${ }^{4,12}$

The gene, currently named PROL1 gene, coding the PRL1 is a precursor protein of opiorphin mature peptide product, identified by Dickinson et al, is expressed in human lacrimal and salivary glands. The concentration of opiorphin in human saliva was quantified as 2.8 to $25.9 \mathrm{ng} / \mathrm{ml}^{13}$

In addition to saliva and human lacrimal tears, the peptide has also been quantified in seminal fluid, milk, blood and urines of humans. Opiorphin also circulates in the reproductive system, notably in the semen of normozoospermic donors and in the milk of lactating women. The highest physiological level of opiorphin is seen in tears and saliva. In human blood the opiorphin physiological concentrations range from 0.3 to $1.1 \mathrm{ng} / \mathrm{ml}$. Males have a higher concentration than females and the level of opiorphin in blood was found to be comparatively less in second trimester of pregnancy among females. ${ }^{14}$

These observations indicate that it is synthetized, secreted and distributed as a paracrine/autocrine and/or exocrine peptide messenger. Prior to the identification of human opiorphin, two identically acting natural inhibitors of the rat membrane bound neutral endopeptidase with analgesic activity were also detected. This include: spinorphin, a heptapeptide extracted from bovine spinal cord and the sialorphin QHNPR-peptide, the functional homolog of human opiorphin in rat. ${ }^{4}$

In the gastrointestinal and urogenital tracts, opiorphin causes colonic contraction in a concentration dependent manner (from $10^{-6}$ to $10^{-4} \mathrm{M}$ concentrations). This opiorphin effect is blocked by naloxone and partially inhibited by $\beta$-funaltrexamine and naltrindole. The MetENK-induced contractile response is significantly enhanced, indicating the involvement of ENK-dependent opioid pathways in the opiorphin-evoked colonic motility. ${ }^{15}$

Intravenous administration of opiorphin $(300 \mathrm{nmol} / 200 \mu \mathrm{g} / \mathrm{kg})$ induces transient increase in blood pressure and heart rate in anesthetized rats (about $40 \mathrm{mmHg}$ and beats/min, respectively). These effects are mediated through the renin-angiotensin system, the sympathetic ganglia and adrenal medulla. ${ }^{16}$

A study assessing the salivary concentration of opiorphin level before and after administration of local anesthesia (LA) showed a significant difference in the levels of salivary opiorphins ranging from 5.96-14.49ng/ml before and after LA administration, suggesting the possible action of local anesthetics on the ENKs. ${ }^{17}$

In spite of the captivating leads of opiorphin peptide, its pharmaceutical development is hindered by its low stability, typical of N-terminal glutamine peptides. ${ }^{12}$ The metabolic half-life of opiorphin is $5 \mathrm{~min}$ owing to it rapid degradation by circulating peptidases. ${ }^{6}$

\section{DIAGNOSTIC IMPLICATION \\ AND \\ THERAPEUTIC}

Opiorphin is the human functional homologue of the rat sialorphin, which is an inhibitor of pain perception. The endogenous opioid peptides, in particular the ENKs, have a pivotal role in the control of pain perception and moodrelated states, including modulation of emotional and or motivational responses. While the peripheral and spinal $\mu$ opioid pathways are involved in the control of nociceptive transmission, the central opioid pathways are preferentially involved in the control of emotional behavior. ${ }^{10}$ This is supported by the complete antagonism of activity of opiorphin by nonselective opioid antagonist naloxone in contast to partial attenuation of antidepression like effect of opiorphin by $\mu$ selective antagonist in force swim test rat model. ${ }^{11} \delta$ opioid agonists also known to facilitate the $\mu$ mediated antinociception while $\mu$ opioid agonists modulate the antidepressant potency of opioid agonists. ${ }^{10}$ Endogenous opiorphin could facilitate adaptive responses to threat-inducing stimuli by potentiating analgesic and antidepressive-like behavior, induced by endogenous enkephalinergic systems, in humans. The greater effectiveness of opiorphin with 
respect to all other peptidase inhibitors suggests that it may produce higher levels of ENK-like peptides, not only protecting endogenous ENKs from hydrolysis, but also stimulating their release. Another important advantage in the use of opiorphin as painkiller agent is that many of the side effects of morphine and morphine-like drugs (such as respiratory depression, sedation, constipation, physical and psychic dependence and tolerance) are absent. ${ }^{5,8,15}$

Table 2: Diagnostic and therapeutic role of opiorphin.

\begin{tabular}{|c|c|}
\hline & Diagnosis \\
\hline \multirow{11}{*}{$\begin{array}{l}\text { Pharmacological } \\
\text { action }\end{array}$} & Analgesic \\
\hline & Anti-tumor activity \\
\hline & Anti-depressant \\
\hline & Panicolytic \\
\hline & Gastro intestinal motility \\
\hline & Cardiovascular effect \\
\hline & Erectile physiology \\
\hline & Sperm motility \\
\hline & Follicular growth and Ovulation \\
\hline & Embryo implantation \\
\hline & Carrier for minerals \\
\hline \multirow{5}{*}{$\begin{array}{l}\text { Potential } \\
\text { biomarker }\end{array}$} & Hyperalgesic syndrome \\
\hline & $\begin{array}{l}\text { Socio-relational behavioral } \\
\text { imbalances }\end{array}$ \\
\hline & Depressive states \\
\hline & $\begin{array}{l}\text { Neuropathic conditions affecting } \\
\text { oral mucosa }\end{array}$ \\
\hline & $\begin{array}{l}\text { Painful oral mucosal lesions and } \\
\text { conditions }\end{array}$ \\
\hline
\end{tabular}

Opiorphin is also suggested as a suitable marker for erectile dysfunction. Opiorphin may have therapeutic implications as a potential initiator of molecular pathways that could be exploited to develop new candidate drugs for the clinical management of pain relief and the alleviation of emotional disorders. Opiorphin can improve certain form of mood disorders, particularly depression without inducing hypo- or hyper-active, anxiogenic- nor anxiolytic-like and amnesic behavioral responses. It could be a biological marker with a potential diagnostic role in various pathological situations, such as hyperalgesic syndromes, depressive states and socio-relational behavioral imbalances. ${ }^{10,11,14}$ Levels of opiorphin in plasma, saliva and urine sample has also been estimated in psycho somatic disorders like burning mouth syndrome (BMS) emphasizing a significant use of opiorphin as a potential biomarker to represent emotional and cognitive imbalances occurring with BMS. However, the direct role of opiorphin in BMS is not supported although its blood levels may indicate a systemic deregulation in these patients. ${ }^{18-20}$

\section{CONCLUSION}

Despite the strong therapeutic potential of opiorphin, its short duration of action, represents a serious obstacle to its successful use in clinical practice. Structural modifications of opiorphin, to improve its bioavailability by increasing its lipophilicity and metabolic stability may change the state of art of treating pain and mood disorders. Conformational changes in chemical structure of opiorphin through structure-activity relationship method provided some functional derivatives of opiorphin, which showed improved metabolic stability and unaltered analgesic activity with respect to the natural peptide. Using liposomes and pegylated liposomes as a carrier for delivery of opiorphin has shown significant improvement in bioavailability of opiorphins. These lipid based molecules have shown effective delivery of the drug to its target site while protecting it from degradation.

As cognitive factors play an important role in modulation of chronic pain, drugs like opiorphin that has modulatory effect on the psychosomatic system can effectively combat such vicious conditions.

Funding: No funding sources Conflict of interest: None declared Ethical approval: Not required

\section{REFERENCES}

1. Williams $\mathrm{AC}$ de $\mathrm{C}$, Craig KD. Updating the definition of pain. Pain. 2016;157(11):2420-3.

2. Bond M. Pain education issues in developing countries and responses to them by the International Association for the Study of Pain. Pain Res Manag. 2011;16(6):404-6.

3. Trang T, Al-Hasani R, Salvemini D, Salter MW, Gutstein H, Cahill CM. Pain and poppies: the good, the bad, and the ugly of opioid analgesics. J Neurosci. 2015;35(41):13879-88.

4. Wollemann M, Rougeot C. Human Opiorphin an Endogenous Inhibitor of Enkephalin-Inactivating Ectopeptidases that Displays Antinociception: A Review. Curr Bioact Compd. 2016;12(4):230-5.

5. Wisner A, Dufour E, Messaoudi M, Nejdi A, Marcel A, Ungeheuer MN, et al. Human Opiorphin, a natural antinociceptive modulator of opioid-dependent pathways. Proc Natl Acad Sci. 2006;103(47):1797984.

6. Bogeas A, Dufour E, Bisson JF, Messaoudi M, Rougeot C. Structure-activity relationship study and function-based peptidomimetic design of human opiorphin with improved bioavailability property and unaltered analgesic activity. Biochem Pharmacol. 2013;2(3):2167-0501.

7. Rosa M, Arsequell G, Rougeot C, Calle LP, Marcelo F, Pinto M, et al. Structure-Activity Relationship Study of Opiorphin, a Human Dual Ectopeptidase Inhibitor with Antinociceptive Properties. J Med Chem. 2012;55(3):1181-8.

8. Jutkiewicz EM. RB101-mediated Protection of Endogenous Opioids: Potential Therapeutic Utility? CNS Drug Rev [Internet]. 2007 Jun 1;13(2):192-205.

9. Poras H, Bonnard E, Dangé E, Fournié-Zaluski MC, Roques BP. New orally active dual enkephalinase 
inhibitors (DENKIs) for central and peripheral pain treatment. J Med Chem. 2014;57(13):5748-63.

10. Javelot H, Messaoudi M, Garnier S, Rougeot C. Human opiorphin is a naturally occurring antidepressant acting selectively on enkephalindependent $\delta$-opioid pathways. J Physiol Pharmacol. 2010;61(3):355.

11. Yang QZ, Lu SS, Tian XZ, Yang AM, Ge WW, Chen Q. The antidepressant-like effect of human opiorphin via opioid-dependent pathways in mice. Neurosci Lett. 2011;489(2):131-5.

12. Sitbon P, Van Elstraete A, Hamdi L, Juarez-Perez V, Mazoit JX, Benhamou D, et al. STR-324, a stable analog of opiorphin, causes analgesia in postoperative pain by activating endogenous opioid receptordependent pathways. Anesthesiol J Am Soc Anesthesiol. 2016;125(5):1017-29.

13. Brkljačić L, Sabalić M, Salarić I, Jerić I, Alajbeg I, Nemet I. Development and validation of a liquid chromatography-tandem mass spectrometry method for the quantification of opiorphin in human saliva. $\mathrm{J}$ Chromatogr B. 2011;879(32):3920-6.

14. Dufour E, Villard-Saussine S, Mellon V, Leandri R, Jouannet $\mathrm{P}$, Ungeheuer MN, et al. Opiorphin secretion pattern in healthy volunteers: gender difference and organ specificity. Biochem Anal Biochem. 2013;2(3):2-11.

15. Tian X, Chen J, Xiong W, He T, Chen Q. Effects and underlying mechanisms of human opiorphin on colonic motility and nociception in mice. Peptides. 2009;30(7):1348-54.

16. Tian X, Chen Y, Bai L, Luo P, Du X, Chen Q, et al. Effects and underlying mechanisms of human opiorphin on cardiovascular activity in anesthetized rats. Eur J Pharmacol. 2015;749:32-8.

17. Al Saffar MT, AL Sandook TA, Y Taha M. A Possible New Concept in the Mechanism of Action of Local Anesthesia. Am J Med Biol Res [Internet]. 2013 Nov 22;1(4):134-7. Available http://pubs.sciepub.com/ajmbr/1/4/5

18. Salarić I, Sabalić M, Alajbeg I. Opiorphin in burning mouth syndrome patients: a case-control study. Clin Oral Investig. 2017;21(7):2363-70.

19. Boucher Y, Braud A, Dufour E, Agbo-Godeau S, Baaroun V, Descroix V, et al. Opiorphin levels in fluids of burning mouth syndrome patients: a casecontrol study. Clin Oral Investig. 2016.

20. Mennini N, Mura P, Nativi C, Richichi B, Di Cesare Mannelli L, Ghelardini C. Injectable liposomal formulations of opiorphin as a new therapeutic strategy in pain management. Futur Sci OA. 2015 Nov;1(3).

Cite this article as: Sujatha S, Priyadharshini R, Nejad NK, Yashoda Devi BK, Shwetha V, Kumar PT, et al. An analgesic to bridge the gap between Narcotics and NSAIDs: opiorphin. Int J Basic Clin Pharmacol 2018;7:1432-6. 